Баденикова Маргарита Викторовна,

доцент, Ангарский государственный технический университет, e-mail: osya_88@mail.ru

ФОРМИРОВАНИЕ КОНЦЕПЦИИ СОВРЕМЕННОГО САДА

Badenikova M.V.

\title{
THE FORMATION OF THE CONCEPT OF A MODERN GARDEN
}

\begin{abstract}
Аннотация. В статье рассмотрены основные стилевые особенности, свойственные садам модернизма.

Ключевые слова: ландшафтный дизайн, модерн, ландшафтные компоненты.

Abstract. The article deals with the main stylistic features peculiar to the gardens of modernism.
\end{abstract}

Keywords: landscape design, modern, landscape components.

История садово-паркового искусства теснейшим образом связана с другими искусствами. В основном, мы различаем стили, связанные с господствующими идеями и «господствующей семантикой» эпохи. Конец XIX - начало XX вB. считается золотым веком садово-паркового искусства. В это время были определены основные пути развития сада, найден баланс между следованием фрормальным законам и поиском новых средств самовыражения.

Для понимания предпосылок рождения нового стиля давайте попробуем погрузиться в ту эпоху, увидеть трудности развития, противоречия и связи с влиятельными идеологическими и философскими течениями, смены творческой направленности в искусстве.

Вторая половина XIX столетия отмечена рядом серьезныХ событий - в Соединенных Штатах разразилась Гражданская война, в Европе также распространялись достаточно радикальные революционные веяния. Разгром Франции и крушение Второй империи, восстание жителей Парижа привело к образованию Парижской Коммуны. Затем последовало подавление Коммуны правительственными войсками. В эти годы повсюду происходили важные события: Великобритания расширяла свои владения в Африке, усиливалась военная активность на Балканах, надвигалась промышленная революция, были сделаны крупные открытия в области инженерного дела, химии, технологии, микробиологии. Философские споры были сосредоточены на таких темах, как подсознательное и рациональное, свобода и необходимость. Бурление, охватившее всю континентальную Европу, вылилось в новый расцвет романтизма, который в свою очередь, вызвал всеобщее стремление к справедливости и демократии. Французское искусство переживало коренные, принципиальные изменения. Художники последовательно начали отказываться от установок, выработанных Парижской школой искусств, предпочитая полную свободу, как в стиле, так и в объектах изображения. Художники, объединявшиеся в группы, были преисполнены решимости сражаться за перемены, которых они жаждали. В 1863 г. в Париже, с разрешения Наполеона III, состоялся 
«Салон отверженных». На выставке демонстрировались около 4 тысяч работ, которые до этого были отвергнуты официальным Салоном искусств. А на всемирной выставке в 1867 г. совершенно новым явлением стала японская графика, которая приобрела популярность благодаря своему эстетизму. Именно японские гравюры открыли художникам - импрессионистам глаза на цвет. По словам Теодора Дюре, «нужно было появиться ... японским гравюрам, для того чтобы кто-либо осмелился сесть на берегу реки и писать ярко красную крышу, белую стену, зеленый тополь, синюю воду». Вторая выставка - «Выставка живописи», организованная в 1987 г., в которой приняли участие только 18 художников, показала, что каждый из представленных мастеров, разрабатывал свой стиль. Под впечатлением от этой выставки, критик Эдмон Дюранти, преданный и активный сторонник молодых художников, опубликовал эссе «Новое искусство».

В истории архитектуры этот период отмечен развитием эклектики (искусство вариаций, смесь эпох и традиций, умение сочетать разные направления). Долгое время понятие эклектики было явно уничижительным. Между тем две особенности архитектурной эклектики должны быть положительно оценены. Первое. Понятие эклектики предполагает выбор лучшего. Второе. Эклектика резко повысила изучение истории архитектуры, создала благоприятные условия для овладения архитекторами культуры архитектурного рисования, культуры «архитектурной детали». Эклектика по сути своей дает возможность создавать новое, не разрушая сложившегося архитектурного облика города. Во второй половине XIX века подверглись реконструкции исторические центры крупнейших европейских столиц во имя более рационального использования пространства и его функциональности. В результате создания новых материалов, таких как сталь и разнообразные сплавы, в городской архитектуре проявились новые веяния - открытые, словно выставленные на показ конструкции. Хрустальный дворец, где размещалась Большая выставка 1851 г., представлял собой уникальное сооружение из стекла и стали. Спроектированный Д.Пакстоном, он стал объектом эпохального эксперимента, целью которого было установить, как могут быть использованы в архитектуре новые промышленные материалы. Железнодорожные вокзалы, металлические конструкции которых великолепно передавали дух новой технологической эпохи, вошли в повседневный обиход. Правда, в типовой, массовой застройке не стало нормой применение новых, нетрадиционных форм и приемов, современных материалов и конструкций. В архитектурной среде главную роль активно, подчас агрессивно, играет пластический образ отдельного здания, будь то вокзал, выставочный павильон, торговый дом или частный особняк. Все изобилие внешнего декора сооружений было рассчитано на то, чтобы зритель и не пытался искать его функционального оправдания, а сразу же настраивал себя на понимание его художественной самоценности, на восприятие той особой красоты, которая наполняет форму духовно-эмоциональным содержанием. Европейская культура развивается под знаком символизма. Событием в области архитектуры стала Эйфеле- 
ва башня, возведенная в 1889 г. для всемирной выставки в Париже: она знаменовала собой триумф «Новой архитектуры».

Садовое искусство второй половины XIX в. развивалось примерно по тем же законам и теми же темпами, что и архитектура, поэзия, живопись. Новые сады отличались разнообразными сочетаниями, свойственными архитектуре эклектизма. Эклектика в садово-парковом искусстве не столько изменяла характер садов и парков, сколько добавляла к ним новые элементы, усложняла парковую систему и разнообразила ее. За предыдущие годы пейзажный стиль достиг совершенства и исчерпал себя. Архитекторы вновь открыли для себя величие и грандиозность регулярного стиля, в сады вернулись геометрически правильные формы. Вновь вернулись балюстрады, выгибные аллеи, подстриженные кустарники и деревья, террасы и фонтаны. Увлечение цветниками достигло исключительного размаха.

Сложно сказать, когда появился первый публичный парк. Известно, что публичные «вечерние» увеселительные сады, продолжавшие традицию садовых праздников XVII - XVIII вв., были распространены по всей Европе. Кроме аллей для прогулок в садах находился просторный концертный павильон, где выступали музыканты и давались театральные представления. В России один из наиболее известных увеселительных садов Москвы - «Эрмитаж», занимал территорию в 8 гектаров и имел два проточных пруда. Водяные фейерверки, таинственные беседки, гастролировавшие коллективы неизменно привлекали в сад разного рода публику. Дворцовые же парки были закрыты для публики, вход, как привилегия, был дарован лишь немногим избранным. Французская революция, национализировавшая королевское имущество, способствовала процессу демократизации садов и парков. Дворцовые парки утратили свой элитарный, придворный характер и превратились в общественные места, куда при наличии костюма могли приходить все желающие. Здесь строились чайные и кофейни, по аллеям разъезжали любители верховой езды, а няни гуляли с детьми. Помимо публичных парков начали создавать бульвары и скверы. Этому способствовала мода на пешие прогулки, пришедшая из Англии и широко распространившаяся в Европе. Еще в конце XVIII в. медики настойчиво заговорили о пользе «моциона» и постепенно бульвары превратились в излюбленное место для прогулок. В России, в частности, появились московское бульварное кольцо и Александровский сад. К середине XIX столетия в большинстве российских городов имелись собственные городские сады, скверы и бульвары. Любопытны были сады при станциях Николаевской железной дороги, соединявшей Петербург и Москву. Николаевская железная дорога была самым большим архитектурным сооружением в мире. Все станции и подсобные здания построены одним архитектором - Тоном - и по существу рассматриваются как единое произведение зодчества. При всех станциях около зданий устраивались сады - посадки из деревьев по разбитому плану, с проведением дорожек, для чего был призван известный тогда садовник из Петербурга - Альварт, устроивший Александровский сад. Эклектика в садово-парковом искусстве в русских 
поместьях не изменила характер усадебных садов. Новые сады, разбивавшиеся на месте старых, сохраняли систему прудов с перепадами их уровней, типичную для Древней Руси. Сохранялись столь любимые «темные аллеи», а так же доминирующее значение в садах и парках лип и дубов, придававших местности одновременно элементы парадности и уюта [1].

Новый взгляд на искусство вообще, и садово-парковое в частности, также связан с движением «Искусства и ремесла», основанным в 1865 г. Уильямом Моррисом. Входившие в него молодые художники выступали против засилья промышленных штамповок, пытались вернуть в искусство ручной труд, а значит, и индивидуальность. Идеи движения оказали влияние на творчество мастеров того времени. При этом не всегда сады разбивались профессиональными архитекторами и садовниками, иногда и сами владельцы принимали участие в их создании, оставляя яркий след индивидуальности на своем творении. Одни мастера привлекали внимание публики к местным, вышедшим из моды цветам, кустам и деревьям, которые высаживали рядом с экзотическими растениями, считая, что главным критерием подбора должны стать благоприятные условия для роста и развития, а также сочетаемость по цвету и форме. Другие высаживали редкие, привезенные из путешествий, растения. Ввозилось огромное число новых цветов и растений из отдаленных стран. В оранжереях специалисты - садоводы выращивали растения по географическим признакам: из Японии, Китая, Америки, Швеции, Швейцарии и пр. Развиваются сады научного типа - ботанические, основная задача которых состоит в том, чтобы продемонстрировать и распространить различные виды привезенных растений, а художественные задачи играют меньшую роль. Таким образом, сады и парки становились своего рода коллекциями. Вместе с тем другие дизайнеры, такие как сэр Р. Блумфилд, выступали за чистоту садового искусства, в особенности против мозаичного смешения садовых и сельскохозяйственных культур. Сад в стиле Блумфилда - это серия пространств, которые являются естественным продолжением дома, следовательно, сад должен проектировать архитектор одновременно с домом. Вместе с садом изменилось и офрормление дома [2].

Следует отметить одно из крупных изменений в садах: появление альпийских горок - нагромождение камней с дорожками, а иногда ручьями и водопадами, между которыми сажались различные низкорослые растения, растущие в различных климатических условиях и в различных частях света. После выхода книги Уильяма Робинсона «Альпийские цветы для садов» в 1870 г., в которой был предложен новый подход к выращиванию горных растений в саду, альпийские горки стали гораздо изящнее и естественнее. А вскоре миниатюрные альпинарии появились практически во всех английских садах, положив начало очень личностному восприятию и романтической трактовке сада. Под влиянием трудов знаменитого дизайнера, опубликованными в журналах «Сад» и «Иллюстрированное садоводство», наряду с помпезными садами аристократии все большую популярность 
приобретают маленькие загородные сады. В европейских странах, прежде всего в Великобритании, частный дом стал просто немыслим без садика, а садоводство превратилось в предмет увлечения и горделивой демонстрации.

Скульптуры и символические постройки стали редки, но в садах стали появляться искусственные элементы: кусочки зеркал имитировали водную гладь, раковины естественные и искусственные, фигурки гномов, птиц и животных, как бы изображающие населяющие сад живые существа. Бурное промышленное развитие позволило дешево и быстро копировать стилистические приемы различных эпох. Многие из этих новаций считались исключительной безвкусицей и проявлением мещанства, но на покупательский спрос это нисколько не влияло.

Чтобы двигаться вперед, нужно было объединить научные открытия, достижения прошлого и новые возможности. В руках у садоводов оказалось такое количество неизвестных прежде растений, что потребовалось нечто большее, чем мозаичность эклектики или строгость научного подхода. Одним из основных направлений садового искусства становятся эксперименты с материалом: внимание садовников все чаще привлекали цвет, текстура и форма растений, в том смысле как их понимает любой художник. Гертруда Джекилл ввела моду на композиции из растений на основе их цветовой гаммы. Архитектор Эдвин Лютайнс, обратившись к садоводству, взял за основу фрормальный сад с четкими геометрическими линиями. Творческий союз Лютайнс - Джекилл привел к рождению нового стиля, соединившего строгость классики и необузданную свободу модернизма.

Модерн - с французского - новейший, современный. Новое направление в искусстве возникло как реакция на эклектизм и копирование исторических стилей прошлого. Стиль Модерн - одно из названий стилевого направления в европейском и американском искусстве конца XIX - начала XX вв. В Бельгии, Великобритании и США оно известно как Ар-нуво, в Германии - Югендстиль, в Австрии стиль Сецессиона, в Италии - стиль Либерти, в Испании - Модернизм. Каждое из этих направлений шло к новому стилю своим путем, определяемым особенностями той или иной национальной художественной школы, но в то же время их объединяло типологическое сходство, что во многом способствовало формированию тех общих межнациональных особенностей, которые позволили впоследствии именовать модерн международным, «космополитическим стилем».

В архитектуре также экспериментировали с материалом: модерн часто сознательно трансформировал природные свойства натуральных материалов, имитируя чуждые им структурные качества. Мастера «нового стиля», с одной стороны, черпали вдохновение в органических формах природы, видели в них источник красоты и целесообразности. С другой стороны, демонстративно нарушали правду действительности, противопоставляя ей свой собственный предметный и духовный мир: придавая стеклу - текучесть, железу - вязкость, бетону - пластичность. Подобная мистификация являлась частью стилизационных принципов [3]. 
Среди тех, кому пришелся по душе новый стиль, был французский художник - импрессионист Клод Моне. В доме художника было большое собрание книг по садоводству. Моне коллекционировал каталоги семян, а из растений компоновал сад так же, как писал картину, обращая внимание на цветовую палитру. Растения подбирались таким образом, чтобы их цветение продолжалось круглый год. Сад был разделен дорогой на две части. Возле дома - верхний сад, спланированный в традиционном стиле: аллеи, увитые вьющимися растениями, дорожки, пересекающиеся под прямым углом, ступени, соединяющие части сада. Наряду с представителями местной флоры здесь росли японские фруктовые деревья, бамбук, пальмы. Любимое детище художника - нижний сад, где были устроены пруды и бассейны. Вода в некоторых прудах подогревалась, и в них цвели роскошные тропические лилии. Над прудом построили тонкий японский мостик - дань увлечению искусством Японии. «Самое прекрасное мое произведение - мой сад», говорил Моне. Именно сад: цветочные заросли, сплетение ветвей, тонкие японские мостики и кувшинки на воде - основной сюжет последних, гениальных в своей простоте и величии, картин Моне [4].

Несмотря на стремительную эволюцию, модерн на всех этапах развития предстает в динамическом равновесии оппозиций функционального и духовного, целесообразного и эмоционального, рационального и интуитивного. Единство и борьба этих противоположностей восходили к двум истокам нового направления в искусстве - рационализму и романтизму.

В первой половине XX века революции и войны, в которые втягивается весь мир, не препятствуют экспериментам и поискам нового. В мире искусств происходит пересмотр прежних представлений о красоте, цвете и пространстве, пришли новые имена и авангардистские движения. Многоголосье художественных тенденций сложилось в новое направление в искусстве Модернизм (от лат. «современный, недавний»). В широком смысле модернизм - «другое искусство» - собирательное название для тех художественных тенденций, которые являются более радикальными, чем художественный стиль «модерн». Главной целью является создание принципиально новых произведений, основанных на внутренней свободе и особом видении мира автором, происходит радикальный отказ от преемственности. Направление модернизма возникло в разные годы, в разных странах. Местные течения не связаны между собой общими стремлениями и идеалами, как и не связаны с национальными традициями искусства своих стран.

Новая архитектура, или модернизм, оказала значительное влияние на садово-парковое искусство. Достижения Ле Корбюзье, Мис ван дер Роэ, Вальтера Гропиуса легли в основу формирования нового взгляда на сад. Многие сады и парки спроектированы архитекторами не случайно. В XX веке искусство ландшафтного дизайна все больше соотносится с архитектурой как в использовании определенного языка и приемов, так и в силе художественного воздействия. Френк Райт, например, воплотил в своих работах идею естественного слияния ар- 
хитектурных сооружений с окружающей природой: план «следует» за местностью, галереи, террасы открываются во внешний мир, осуществляя, таким образом, принцип «органической» архитектуры. Райт отказался от четких границ между естественным и рукотворным. Он использовал камень, кирпич, бетон, но на опорах дома растет трава; лестница становится частью холма, каменная терраса с бассейном воспринимается как естественный выход породы на поверхность. Лаконизм архитектурного языка потребовал того же и от окружающего ландшафта.

После Второй мировой войны тон в искусстве ландшафтного дизайна задавали американцы. Создателем сада нового типа, отвечающего модернистским принципам, названного калифорнийским, считается Томас Долливер Черч. Благодаря мягкому климату сад в Калифорнии воспринимался как продолжение дома, как еще одна комната. Сад становится местом для вечеринок, барбекю, занятий спортом, детских игр. Здесь естественно соседствуют беседка, увитая зеленью, широкие дорожки, бассейны и места для парковки. Возникла необходимость создания сада не требовавшего пристального ухода. Дизайнер провозгласил основной принцип современного сада: единство дома и сада; функциональность - т.е. следование служебных участков потребностям человека, а декоративных участков - желаниям владельцев. В садах Черча отсутствовали диагональная симметрия, ффиксированная точка обзора, и большие отгороженные друг от друга участки. Сад не имел ни конца, ни начала, прекрасный вид открывался с любого места. Черч освободил сад от давления традиций и законов ландшафтного проектирования. Теперь можно было все [2].

Таким образом, понятие «сад» постоянно трансформируется, наполняясь новым смыслом. Это уже многоплановый феномен, в котором соединены разные функции и искусства. В целом с середины XIX - начала XX вв. садово-парковое искусство не выдвинуло принципиально новых эстетических концепций, подобных Возрождению, барокко и классицизму. Но можно выявить общие тенденции в подходе к решению планов садов, в аранжировке зелени, использовании характерных приемов садово-паркового искусства нового стилистического направления.

Итак, основные отличительные признаки, свойственные садам модернизма:

- особенности планировки. Модерн впервые соединил европейские и восточные художественные традиции. Прежде всего, это выразилось в свободной планировке, асимметричном построение композиции. Поскольку асимметрия это всегда некая недосказанность, философия, в которой заложен источник дальнейшего развития, нет уравновешенных сил, статичности. Выявление геометрии формы является главной задачей, но геометрия не означает использования только геометрических форм. Сад может быть и пейзажным, в этом случае, в плане преобладают геометризированные кривые линии, образовывающие изысканнопретенциозную сеть дорожек, «амебообразные» водоемы, газоны, площадки. Либо сад архитектурный - в плане преобладают прямые, четкие линии аллей, дорожек, каналов и ровные плоскости газонов. Этот сад отражает образы и формы 
различных сооружений, это как бы попытка пересказать архитектуру языком ландшафта. Характерная черта - тема должна повторяться в нескольких элементах, создавая, таким образом, некий ритм. Например: квадратный газон - квадратный водоем - орнамент из квадратов на ограде - прямоугольные элементы мощения и т.д. [5].

- функциональное зонирование. Для деления участка на функциональные зоны тоже много средств: сплошные стены, ковка, живые изгороди, могут быть использованы и экраны, подпорные стенки из бетона, природного камня, или металла. Либо разделение может быть слегка намечено и зоны не имеют видимых границ, выявление осуществляется за счет перепадов высот - террасирования, применением различных видов мощения, цветочных рабаток.

- использование ландшафтных компонентов.

Растения. Основа посадок в саду - крупные деревья, кустарники, многолетники. Фактура, размер листьев, тип ствола и кроны должны соответствовать основной концепции, которая определяет основной смысл, идею, в нем заложенную. Главное - полное отсутствие сложных растительных композиций. Живописно разросшийся кустарник соседствует с четкой линией дорожки, а математическая точность аллей - с отпущенными на свободу цветами, образующими сплошные живые ковры. Специально подобранные и высаженные растения меняются с годами почти без участия садовника, предоставляя природе свободно проявить себя.

Вода. Занимает в саду одно из центральных мест. Ее присутствие выражается в самом разнообразном виде: неподвижная - водоемы геометрической формы, приподнятые (желательно с какой-то интересной деталью); водоемы - каналы, либо вода образует шумные водопады и ручьи, перескакивая с камня на камень.

Дорожки в саду, ступени, подиумы и лестницы. В саду этого стиля много мощений, применяется и натуральный камень, и кирпич, и бетонные плиты, и отсыпки из щебня или гальки. Использование разных цветов в мощениях, комбинирование разных фактур покрытий подчеркнет дизайнерскую идею, индивидуальность. При выборе материала необходимо ориентироваться на архитектуру вашего дома, к какому временному периоду относятся архитектурные детали, которые вы хотите отразить на своем участке.

Аксессуары допускаются, но должны быть тщательно подобраны. Вазоны четких форм, материал любой, кроме откровенного пластика. Одна абстрактная фригура. Как элемент декора, возможно, использовать шары из бетона или стеклянные, зеркала, выразительные садовые ширмы - все в соответствии с основной идеей и с чувством меры. Главное - сдержанность. Один тщательно подобранный предмет усилит модернистскую концепцию: «меньшее есть большее».

Таким образом, современный сад - не столько палисадник для коллекции растений или место для развлечений, сколько способ проявления художественного духа, священное пространство, дающее возможность творить вместе с домом и 
его душу - сад. На сегодняшний день источниками вдохновения могут служить и произведения искусства - воспоминания о картинах, примеры оформления садов итальянского Ренессанса и храмовых садов Киото. Либо возможно взять за основу классический английский сад с дорожками и цветочными бордюрами, и населить его местной фолорой, которая нарушит границы приличия буйством цвета, разнообразием форм и неудержимым ростом. Также возможно экспериментировать с водой и искусственными материалами, отдать предпочтение ярким краскам, устраивая водопад из трубы на фроне ярко окрашенной стены, соединять абстрактные плоскости с природными элементами. К созданию сада можно подходить с точки зрения дизайнера, выстраивая план, можно с точки зрения художника, превращая сад в яркое многоцветное полотно, а возможно скульптора, идущего от формы и фрактуры материала. Также возможно чередование совершенно разных концепций сада в одном пространстве, при этом они не вступают в диссонанс, так как отражают новое стилистическое направление, родственное архитектуре «модерна». Слово «модерн» в сочетании с любым словом в дизайне обозначает нечто особое в сравнении с просто современным решением.

Если вы находитесь в поиске идей и форм для создания своего сада, в котором отразилось бы ваше уникальное видение мира, пожалуй, этот стиль для вас. Все средства в целом просты, при этом сад может выглядеть невероятно эффректно, и в уходе он не сложен. Стиль применим к любому участку, здесь ведь не важно «что», а важно «как».

\section{ЛИТЕРАТУРА}

1. Лихачев Д.С. Поэзия садов. С.-Петербург: Наука, 1991 г. 359 с.

2. Ананьева Е. Самые красивые и знаменитые парки и сады. М.: Аванта, 2004 г. 177 c.

3. Борисова Е.А. Русский модерн. 1990г. 149 с.

4. Рапелли П. Art Book Моне. М.: АСТ Астрель, 2002 г. 124с.

5. Воронова О.В. Сам себе ландшафтный дизайнер. М.: Эксмо, 2008 г. 65 с. 